\title{
Automobile Engine Block Machining Line Simulation
}

\author{
Fuping $\mathrm{Li}^{1, \mathrm{a}}$, Zheng Wang ${ }^{2, \mathrm{~b}}$ and Zhifeng $\mathrm{Liu}^{2, \mathrm{c}}$ \\ ${ }^{1}$ Beijing University of Technology, Beijing 100022, China; \\ ${ }^{2}$ Beijing University of Technology, Beijing 100022, China; \\ ${ }^{3}$ Beijing University of Technology, Beijing 100022, China. \\ Alifp@bjut.edu.cn, bwang_zheng_@live.cn, 'Izf@bjut.edu.cn
}

Keywords: Plant Simulation, automobile engine block, machining line.

\begin{abstract}
In this paper, using the production system simulation software Plant Simulation to model and simulate an automobile engine block machining line, and then analysis the simulation data. Experimental data shows that the production line program has a strong production capacity and good economic, which can be implemented.
\end{abstract}

\section{The basic steps of Simulation and Modeling}

General computer simulation activities include three stages, which are preparation, implementation and evaluation. The main aspects of the various stages included in the figure below.

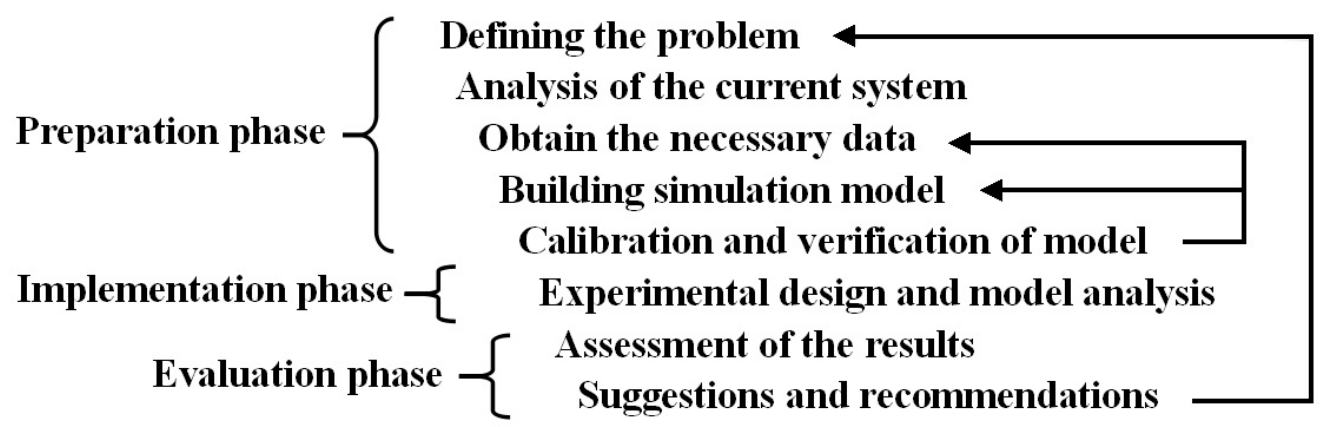

Fig. 1 Computer simulation steps to solve the problem

In the preparation stage is mainly on the issue of quantitative or qualitative description and Clear purpose and mission of the simulation. Get Comprehensive and in-depth understanding of the system through investigation and analysis and then abstract and separate the problem. Isolating study object from the complex problems, which can be reflected the characteristics by, to describe the system in detail as possible.

According to the set simulation target, completing selection, organization, abstraction and simplification of the system, then build the simulation model. The main contents that needed to be consider of when modeling are: System processes, operating procedures and logical relationships. Start by establishing a relatively simple model, which reflect the principal contradiction of the system, And then gradually to supplement and improve it. The complexity of the model should adapt the research objectives you want to achieve.

The implementation phase of work includes experimental design, experimental run and model validation. The assessment phase of the work is to read and interpret the results of the simulation, for Illustrating the effect of the decision variables to the system.

\section{Automobile engine block machining line systems analysis}

Automobile engine block machining line design. The program reference certain engine block production line, Production line consists of five sets of CNC, 3 sets of plane, 2 sets of online gages, 2 washing machine, one honing machine and two auxiliary. in addition to offline gages, the outside 
equipment include one CMM and one coordinate washing machine.

The process production line use U-shaped and annular layout, and the entire cylinder line use parallel, serial hybrid arrangement. Since most CNC have longer beats, they are divided into A/B two parallel modules. Auxiliary equipment, washing machine and honing machine have shorter beats, so they use the serial arrangement. Since the box parts are similar in processing complexity and processing time, when shunting parts, use the control strategy of percentage. The two machining centers are average used averagely, and each fraction was 50\%, making maximum utilization of the machining center. Layout diagram is shown below.

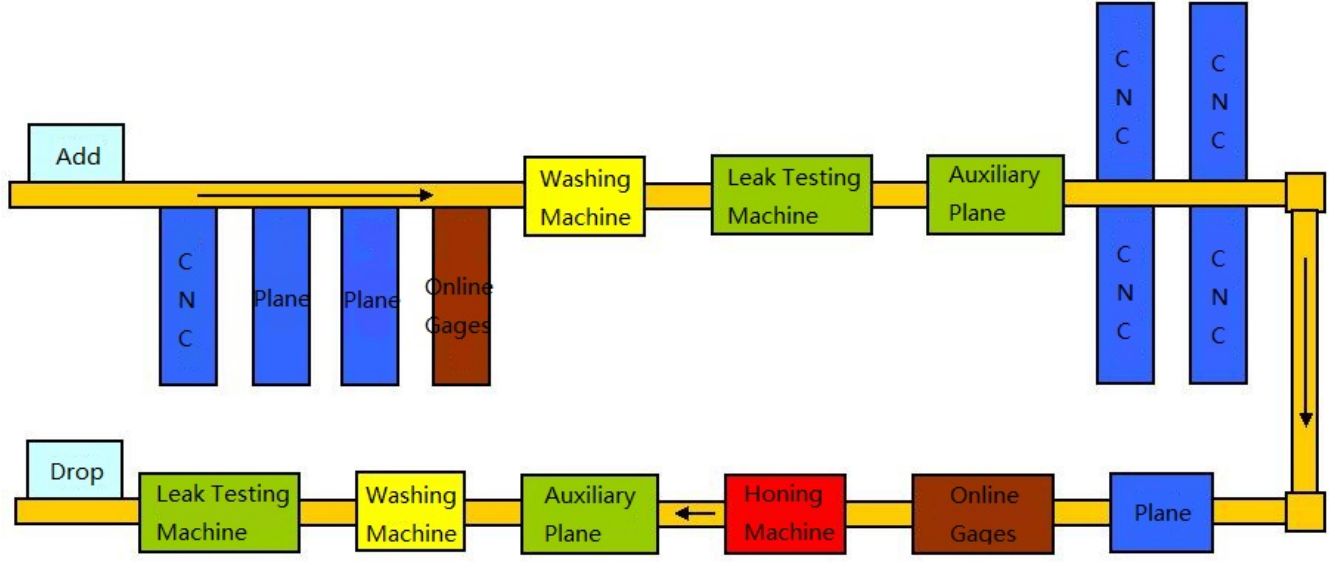

Fig. 2 Production line layout1

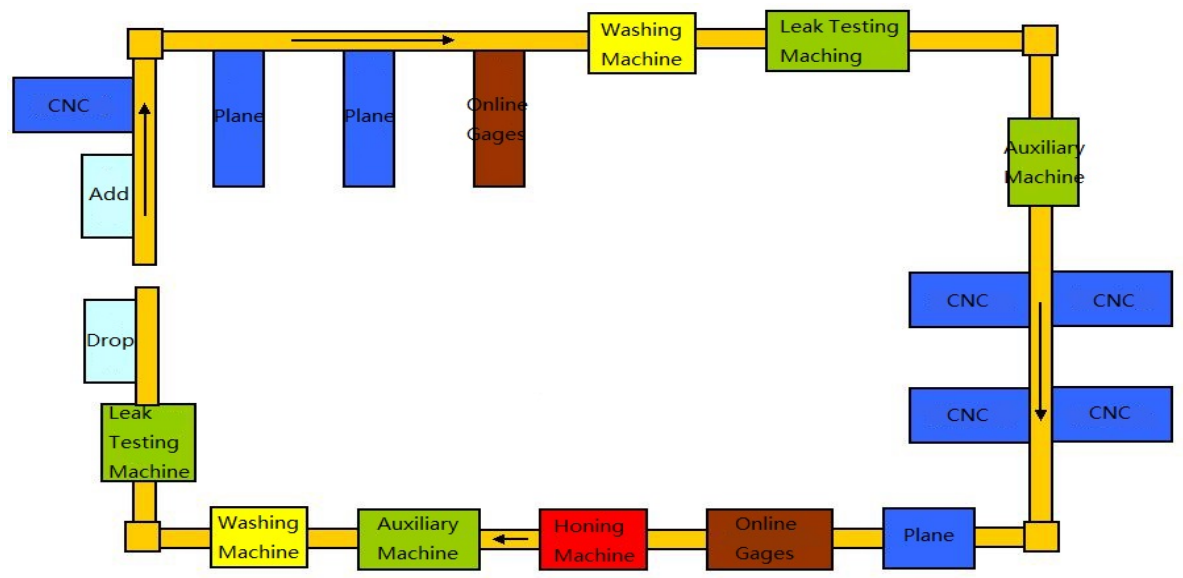

Fig. 3 Production line layout2

\section{Creation of the simulation model}

\subsection{The basic modeling steps of Plant Simulation.}

1.Selection of the object entity: Select the appropriate object according to the function that the system of simulation modeling need to achieve,corresponding software Plant Simulation function in the object. Mapping relationships between entities and software objects are shown in Table 1, For an object not in the software, you can create your own,Plant Simulation provides a good secondary development environment.

2.Construction of the system layout: According to the actual assembly line layout, drop the required libraries from the toolbox or drag to the appropriate hierarchy.

3.Determination of the object flow: According to the actual production process systems, link model objects and build the basic flow simulation system.

4.Determination of the parameters and rules: In order to realize the function of the actual system, the model object must be set and the corresponding rules are written in the software, which can be completed by using method in the software. 
5.Model Debugging: First, the model initialization, and then run the debugger. If inconsistent with the actual, return to step 3 or 4 , keep the constant debugging until a practical function is completed.

The basic idea of this model are:

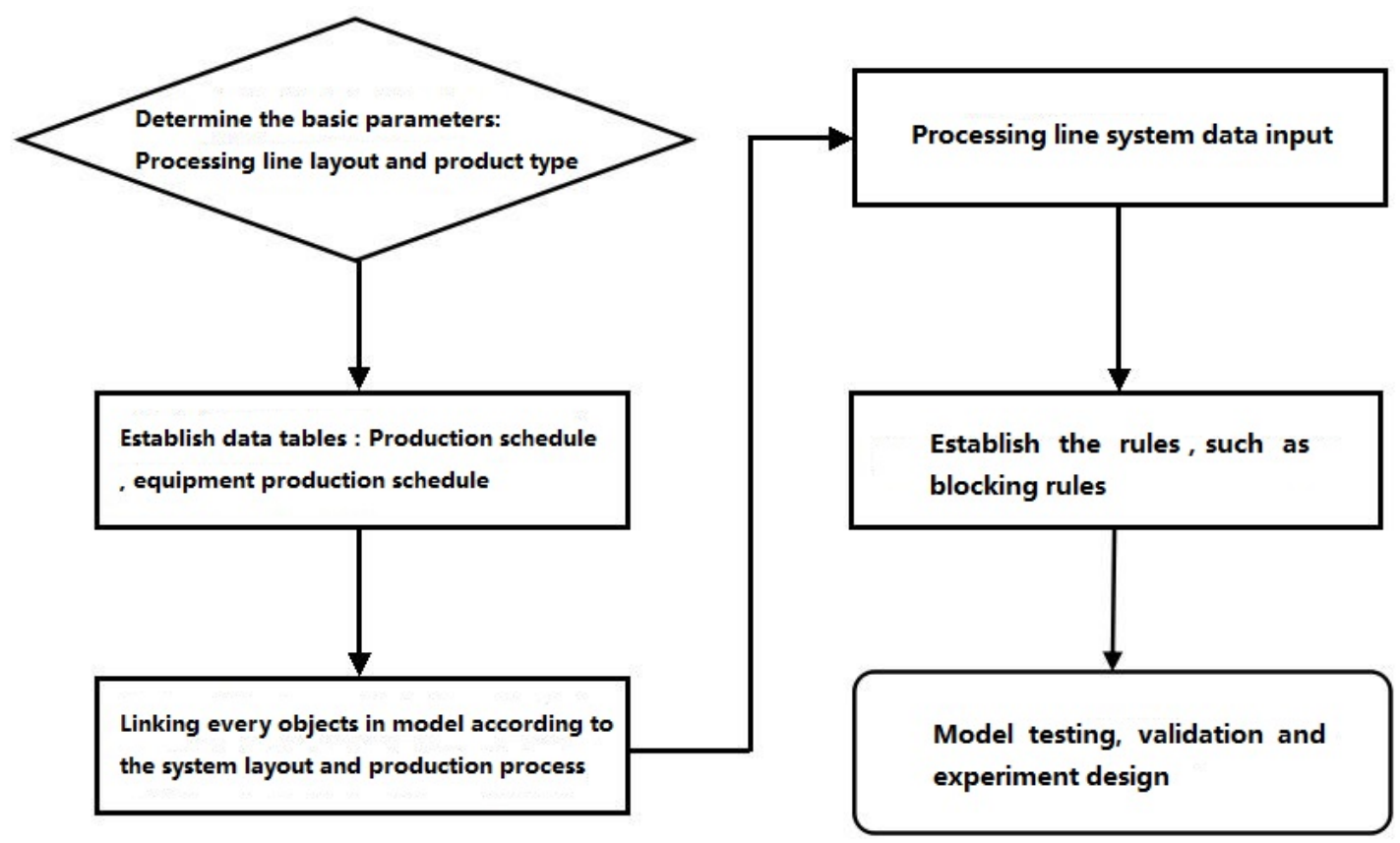

Fig.4 The basic idea of modeling

\subsection{Creation of the basic model layout.}

According to the system layout and production processes as well as the analysis of mixed assembly line, select the appropriate object library into the model layer and then establish the basic Plant Simulation simulation models based on the production model of the actual adjustment position, size and length.

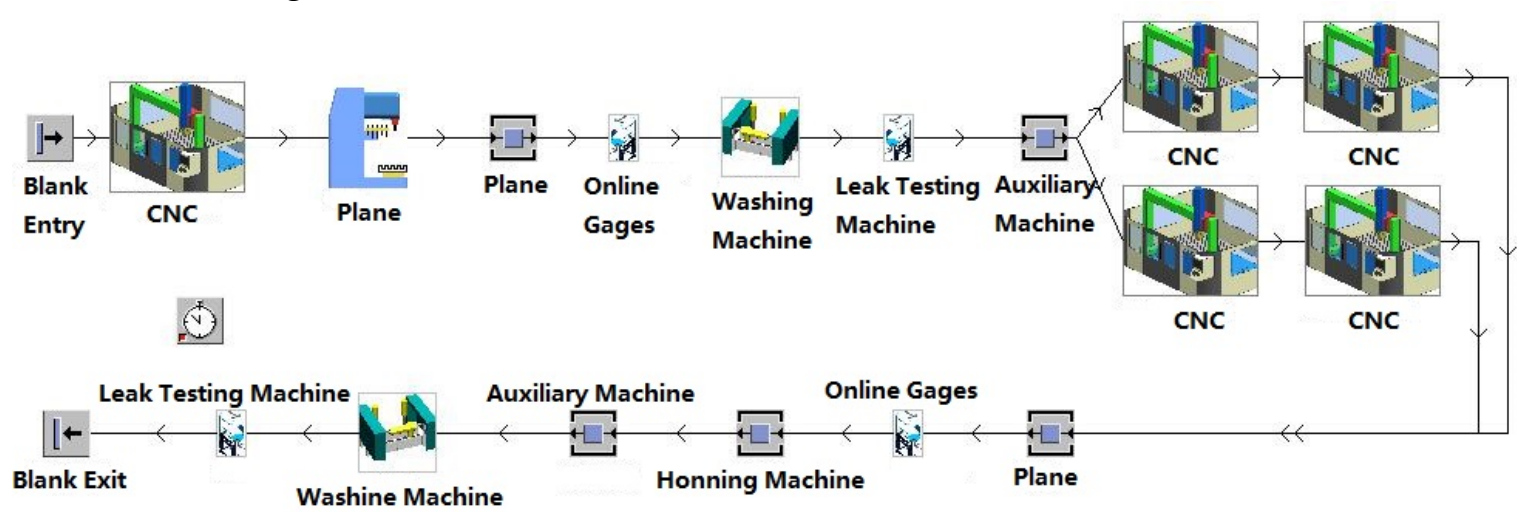

Fig.5 Cylinder production line simulation model program1 


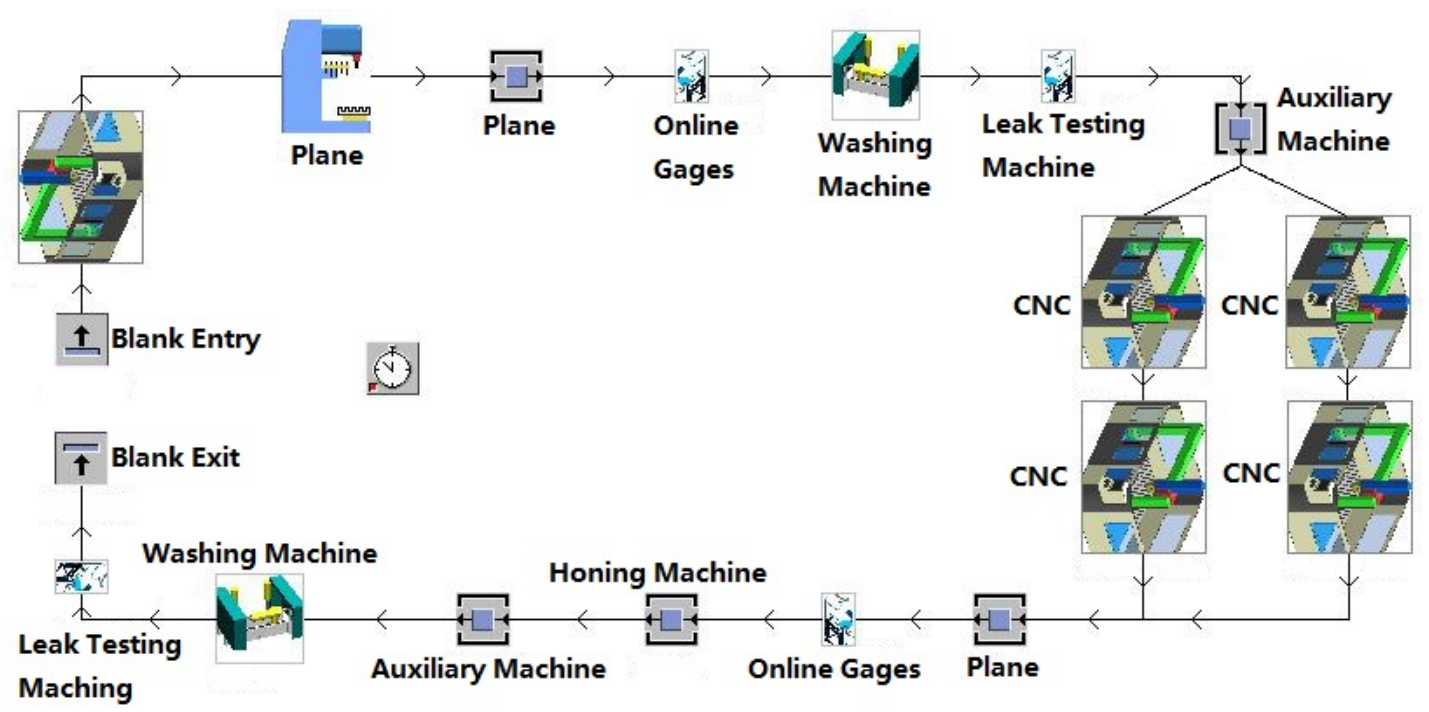

Fig.6 Cylinder production line simulation model program2

\section{The execution of Processing line simulation}

\subsection{The execution of Cylinder block machining line simulation.}

The running processes of automobile engine block machining line are as follows: After into the automatic raceway, the blank successively transported by the rail to each station, then transported by rail to idle CNC Machining Center (CNC). After the processing is completed, Track will move the blank out of machining center. The inspected blank will exit the system when it completed all the steps.

Table 1 Production line simulation program tact

\begin{tabular}{|c|c|c|c|c|c|}
\hline Station & Equipment Category & Beat & Station & $\begin{array}{c}\text { Equipment } \\
\text { Category }\end{array}$ & Beat \\
\hline OP10 & CNC Machine & 74.9 & OP110A & CNC Machine & 765 \\
\hline OP20 & Plane & 73.3 & OP110B & CNC Machine & 10.5 \\
\hline OP30 & Plane & 79.8 & OP160-1 & Plane & 76.7 \\
\hline OP35 & Online Gages & 79.1 & OP160-2 & Online Gages & 76.2 \\
\hline OP40 & Washing Machine & 74.8 & OP210 & Honing Machine & 72.1 \\
\hline OP50 & $\begin{array}{l}\text { Leak Testing } \\
\text { Machine }\end{array}$ & 50 & OP220 & $\begin{array}{l}\text { Auxiliary } \\
\text { Machine }\end{array}$ & 73.5 \\
\hline OP60 & Auxiliary Machine & 74.1 & OP230 & Washing Machine & 80.5 \\
\hline $\begin{array}{l}\text { OP70A } \\
\text { OP70B }\end{array}$ & $\begin{array}{l}\text { CNC Machine } \\
\text { CNC Machine }\end{array}$ & 75.8 & OP250-2 & $\begin{array}{l}\text { Leak Testing } \\
\text { Machine }\end{array}$ & 33.8 \\
\hline
\end{tabular}

When The system running, Simulation entity triggered by the simulation clock according to different control strategies, forming a event simulation of the discrete system, and change the operating state of the entity. Manufacturing resource of the system interaction, forming a specific process. If the parts and trays go into the production line as $1 \mathrm{~min}$ intervals, using the above table tact, simulating 8 hours on the production line, its utilization is shown in the following table: 
Table 2 Production line simulation utilization

\begin{tabular}{cccccc}
\hline Station & Equipment Category & $\begin{array}{c}\text { Equipment } \\
\text { utilization }\end{array}$ & Station & Equipment Category & $\begin{array}{c}\text { Equipment } \\
\text { utilization }\end{array}$ \\
\hline OP10 & CNC Machine & 93.87 & OP110A & CNC Machine & 46.75 \\
OP20 & Plane & 91.62 & OP110B & CNC Machine & 46.73 \\
OP30 & Plane & 99.49 & OP160-1 & Plane & 93.19 \\
OP35 & Online Gages & 98.30 & OP160-2 & Online Gages & 92.32 \\
OP40 & Washing Machine & 92.71 & OP210 & Honing Machine & 87.12 \\
OP50 & Leak Testing Machine & 61.81 & OP220 & Auxiliary Machine & 88.55 \\
OP60 & Auxiliary Machine & 91.33 & OP230 & Washing Machine & 96.68 \\
OP70A & CNC Machine & 46.59 & OP250-2 & Leak Testing & 40.49 \\
OP70B & CNC Machine & 46.57 & & Machine & \\
\hline
\end{tabular}

Simulation results show that eight hours of production parts 345, in article number 16.

\section{Conclusion}

This section use a car engine cylinder block production line for example. Using simulation technology to simulation and analysis automobile engine cylinder block production line design. Experimental data shows that the production line program has a strong production capacity and good economic, which can be implemented.

\section{Acknowledgments}

This work was financially supported by Jing-Hua Talents Project of Beijing University of Technology.

\section{References}

[1] Rekide B, Pierre De Lit. Designing Mixed-product Assembly Lines[J]. IEEE Transactions and Automation. 2000, 3(16): 269-270.

[2] Balas E. An Additive Algorithm for Solving Linear Programs with Zero-one Variables[J].

Operations Research. 1965, 13: 517-546.

[3] Gomory R E. On the Relation Between Integer and Non-integer Solution to Linear Programs.

Proceedings of the National Academy of Science. 1965, 53: 260-265.

[4] Zeigler Bernard P, Praehofer Herbert. Theory of Modeling and Simulation[M]. Academic Press,2000: 13-15.

[5] Thomopoulos Nick T. Line Balancing-Sequencing for Mixed-Model Assembly[J]. Management Science. 1967,14(2): 59-75.

[6] Y.Monden. Toyota Production System[M]. Institute of Industrial Engineers, Atlanta, GA, 1983.

[7] Miltenburg J. Level Schedules for Mixed-Model Assembly Lines in Just-In-Time Production Systems[J]. Management Science. 1989,35(2): 192-207

[8] Yow Y L, Matheson L A. Sequencing Mixed Model Assembly Lines with Genetic Algorithms[J]. Computers \& Industry Engineering. 1996’30(4): 1027-1036.

[9] Rubinovitz J, Levitin G. Genetic Algorithm for Assembly Line Balancing[J]. International Journal of Production Economics. 1995, 41: 343-354.

[10] Sumichrast R T, Russell R S, Taylor B W. A Comparative Analysis of Sequencing Procedures 
for Mixed-Models Assembly Lines in Just-In-Time Production SystemfJ]. International Journal Production Research. 1992, 30: 199-214.

[11] Bard J F, Shrub A. Sequencing Mixed-Model Assembly Lines to Level Parts Usage and Minimize Line Length[J]. International Journal of Production Research. 1994, 32: 2431-2454.

[12] Hyun C J,Kim Y K. A Genetic Algorithm for Multiple Objective Sequencing Problems in Mixed Model Assembly Lines [J].Computers and Operations Research. 1998, 25(7-8): 675-690.

[13] McMuIIen P R. JIT Sequencing for Mixed-Model Assembly Lines with Setups Using Tabu Search[J]. Production Planning and Control. 1998,9(5): 504-510.

[14] Mansouri S A. A Multi-Objective Genetic Algorithm for Mixed-Model Sequencing on JIT Assembly Lines[J]. European Journal of Operational Research. 2005, 167(3): 696-716.

[15] Yang T,Tseng L. Solving a Multi-Objective Simulation Model Using a Hybrid Response Surface Method and Lexicographical Goal Programming Approach-a case Study on Integrated Circuit ink-marking Machines. Journal of the Operational Research Society. 2002, 53: 211-221.

[16] Wolfgang Kuhn. Digital Factory - Simulation Enhancing the Product and Production Engineering Process[C]. Winter Simulation Conference, Monterey, CA, USA, 2006: 1905-1906.

[17] Rekiek B,Lit P De. Hybrid Assembly Line Design and user's preferences[J]. International Journal of Production Research. 2002,40(5): 1095-1111.

[18] HUANG PHILIP Y. A Comparative Study of Priority Dispatching Rules in a Hybrid assembly/job Shop[J]. International Journal of Production Research. 1984, 22(3): 375-387.

[19] Kubiak W, Sethi SP. A Note on "Level Schedules for Mixed-Model Assembly Lines in Just-In-Time Production Systems"[J]. Management Science. 1991, 37: 121-122. 